\title{
Normalization of thyroid hormone levels in patients with either hyper- or hypothyroidism results in a profound change of atrial natriuretic peptide (ANP) levels
}

\author{
George Koukoulis ${ }^{1}$, Antonis Polymeris ${ }^{2}$, Ioanna Tzavara ${ }^{2}$, \\ Dimitrios Pappas ${ }^{3}$, Nicke Thalassinos ${ }^{2}$
}

\begin{abstract}
${ }^{1}$ Department of Internal Medicine, School of Medicine, University of Thessalia Larissa, Greece, ${ }^{2}$ Department of Endocrinology, Diabetes and Metabolism, Evangelismos General Hospital, ${ }^{3}$ Nuclear Medicine Unit, Hellenic Airforce and V.A. General Hospital, Athens, Greece
\end{abstract}

\begin{abstract}
Atrial Natriuretic Peptide (ANP) is a hormone produced by cardiac atrial myocytes. Thyroid hormones may affect its release. The aim of this study was to analyze the effect of hyper and hypothyroidism on the secretion of ANP and its relationship with the changes of the renin-angiotensinaldosterone system. Plasma ANP concentration as well as plasma renin activity (PRA) and aldosterone (ALDO) were measured in 21 patients with hyperthyroidism, 12 patients with hypothyroidism and 29 normal controls. Moreover, in 5 hyperthyroid and 8 hypothyroid patients hormones measurements were performed at diagnosis and 15, 30, 45 and 60 days after starting the appropriate therapy. Statistical analysis was performed employing the Wilcoxon two sample test to compare the ANP levels in normal and hyper or hypothyroid patients while the pairwise comparisons were evaluated using the Spermans rank correlation. Partial correlation and regression models were used to examine the joint effects of multiple predictors on ANP. ANP levels were significantly higher in hyperthyroid (mean \pm SEM, $17 \pm 1.7 \mathrm{pmol} / \mathrm{L}, \mathrm{p}<0.001)$ and lower in hypothyroid patients $(6.18 \pm 1.14 \mathrm{pmol} / \mathrm{L}, \mathrm{p}<0.01)$ compared to normals $(10.35 \pm 0.59 \mathrm{pmol} / \mathrm{L})$. In the hyperthyroid patients following treatment with antithyroid drugs plasma ANP levels reached normal values after 15 days and remained stable thereafter. In the hypothyroid patients, ANP levels increased gradually following initiation of treatment with thyroxine, reaching values comparable to controls at day 45. PRA was significantly higher only in hyperthyroid patients compared to controls. ALDO concentrations were not different in all groups studied. No correlation was found between plasma ANP levels and T3, T4, TSH, PRA and ALDO levels in the individual groups, while a positive correlation for $\mathrm{T} 3(\mathrm{r}=0.610, \mathrm{p}<0.01), \mathrm{T} 4(\mathrm{r}=0.653, \mathrm{p}<0.01)$ and pulse rate $(\mathrm{r}=0.704, \mathrm{p}<0.01)$ and negative correlation with TSH $(r=-0.519, p<0.01)$ was found when all groups were pooled together. In conclusion, our data indicate that thyroid hormones affect positively ANP secretion from cardiac myocytes. This effect may be, at least in part, indirect via hemodynamic alterations.
\end{abstract}

key words: ANP, ANF, thyroxine, atrial stretch, natriuresis

Address correspondence and requests for reprints to:

George N. Koukoulis, Irinis 25, 15342 Athens, Greece, Tel. (301) 6008577, Fax Numb. (301) 779 6568, e-mail: koukl@hotmail.com

Received 03-12-2001, Revised 13-02-2002, Accepted 03-03-2002 


\section{INTRODUCTION}

Atrial natriuretic peptide is a hormone that links the heart to the kidney in the regulation of volume-arterial pressure homeostasis ${ }^{1,2}$. ANP produced and released from cardiac atrial myocytes induces marked natriuresis, diuresis, vasodilation and lowering of blood pressure $^{1,3}$. Moreover, it decreases water and salt intake ${ }^{4-7}$. ANP vasorelaxant action has been demonstrated in a variety of preconstricted tissues as well as in isolated arteries and arterioles from several vascular beds ${ }^{8-11}$. ANP has been shown to be particularly effective in antagonizing contraction of rabbit aorta induced by angiotensin II (Ang-II $)^{9}$. This effect and the marked and sustained suppression of both renal renin secretion and plasma renin levels after ANP infusion in normal dogs ${ }^{12,13}$ suggest that ANP suppresses the renin-ang-II axis. It is possible that the ANP system helps to protect the heart from volume and pressure overload ${ }^{14}$ acting directly on the myocardium and indirectly affecting mechanisms that are involved in the regulation of the peripheral circulation.

Studies in rats indicated that thyroid hormones increase ANP release both in vivo and in vitro ${ }^{15,16}$. Furthemore, human studies revealed that plasma ANP levels are significantly higher in hyperthyroid and lower in hypothyroid patients compared to euthyroid controls ${ }^{(17-21}$. ANP levels return to normal following appropriate treatment. It should be noted, however, that in at least one study this does not appear to be the case; hyperthyroidism and hypothyroidism were not followed by changes in plasma ANP levels ${ }^{22}$.

To further assess the changes in ANP levels associated with endogenous thyroid hormones excess or deficiency and the changes brought about by treatment, plasma ANP levels were measured in hyperthyroid and hypothyroid patients at diagnosis and following appropriate therapy. Moreover, PRA and serum ALDO were simultaneously measured to investigate their possible relationship to ANP changes.

\section{PATIENTS AND METHODS}

Plasma ANP concentrations were measured in 21 patients with hyperthyroidism (12 women and 9 men, aged 20-65yr, median 33yr), 12 patients with hypothyroidism (5 women and 7 men, aged 22-67yr, median 42yr) and twenty-nine normotensive healthy subjects ( 6 women and 23 men, aged 20-59yr, median 36yr) who served as controls. In addition, in 5 hyperthyroid ( 2 women and 3 men; aged 21-49yr, median 39yr) and 8 hypothyroid (4 women and 4 men; aged 28-65yr, median 47yr) patients plasma
ANP levels were also measured before and 15, 30, 45 and 60 days after starting the appropriate therapy. Analogous measurements were made in a control group of 6 normotensive healthy subjects ( 4 women and 2 men, agematched).

The diagnosis of hyperthyroidism and hypothyroidism was confirmed by thyroid function tests. The hyperthyroid patients were treated only with carbimazole (30-40 $\mathrm{mg}$ /day) while the hypothyroid patients were treated with L-thyroxine. All patients and controls were on free diets except the group of patients followed during therapy who consumed diets with 3 grams $\mathrm{NaCl}$ per day. Patients with congestive heart failure, arrhythmia and renal disease or patients taking any medication other than the above mentioned were excluded from the study. The protocol approved by the ethics committee of the HAF and VA General Hospital.

Hormone measurements were carried out in the morning between 8 and 9 AM after an over night fast. The 5 hyperthyroid and 8 hypothyroid patients who were followed during therapy as well as the 6 healthy subjects, who served as controls, were hospitalized for 48 hours on each study occasion. Patients remained in supine position either overnight or for at least half an hour before blood collection. Blood pressure and heart rate were measured before peripheral venous blood samples were obtained. Plasma ANP levels, PRA and serum levels of T4, T3, TSH, ALDO, creatinine, sodium and potassium were determined in all patients. In the patients followed during treatment, serum free T4 (FT4), free T3 (FT3), 24-hour urinary ALDO, creatinine and electrolytes were determined in addition to the above mentioned parameters.

For ANP determination, venous blood was drawn directly into ice-chilled disposable glass tubes containing EDTA $(1 \mathrm{mg} / \mathrm{ml})$ and $500 \mathrm{IU} / \mathrm{ml}$ approtinin. Plasma was immediately separated by centrifugation for $15 \mathrm{~min}$ utes at $4^{\circ} \mathrm{C}$ and stored frozen at $-20^{\circ} \mathrm{C}$ until the assay which was performed within 2 months. Plasma ANP was extracted following sample acidification and loading onto proactivated C18 octadecyl silica cartridges (Sep-pak C18, Waters Associates, Milford, MA). ANP was eluted with $4 \mathrm{ml} 80 \%$ acetonitriline- $10 \% 0,01 \mathrm{~N} \mathrm{HCl}$ and lyophilized. After reconstitution, samples were kept at $-20^{\circ} \mathrm{C}$ until ANP measurement. Plasma ANP levels were measured by RIA. For the plasma ANP determination of the patients studied during therapy and the six subjects who served as controls of these groups an antiserum to human ANP(1-28) which has $<0.01 \%$ cross-reactivity with ANP7-28, ANP13-28 and ANP18-28 (Amersham 
Int.,UK) was used. For all other determinations of the plasma ANP an antiserum to human ANP(1-28) was used which has $109 \%$ and $127 \%$ cross reactivity, respectively, with ANP5-28 and ANP7-28 and $<0,2 \%$ cross reactivity with ANP13-28, ANP18-28 and ANP1-11 (Nichols Institute Diagnostics ltd, UK). Each sample was assayed in duplicate and all samples of each patient were measured in the same assay. The recovery of ${ }^{125}$ I ANP from the cartridges was $78 \pm 2 \%$. Assay results have been corrected for recovery.

Plasma renin activity and serum ALDO, T4, T3, FT4, FT3 and TSH concentrations were determined using commercial RIA kits. Twenty-four-hour urine aldosterone levels were also measured using RIA kits. Serum and urine creatinine and $\mathrm{Na}+$ and $\mathrm{K}+$ were measured by routine laboratory methods.

\section{STATISTICAL ANALYSIS}

Normal distribution of the measured variables was checked by Kolmogorov-Smirnov test. Differences between normal subjects and hyperthyroid or hypothyroid patients were compared by unpaired t-test. One-way analysis of variance was used to analyze serial changes in plasma ANP levels and the other measured parameters in hyperthyroid and hypothyroid patients. Association between ANP and total T3, total T4, FreeT3, FreeT4 and TSH in hyperthyroid or hypothyroid patients was tested with Pearson correlation coefficient. Association of the above variables in pooled together patients and normal controls was examined after log-transformation. To examine the influence of serum T3, T4 and Pulse rate (PR) on the cardiac ANP production, a multiple linear regression model was used after log-transformation. Results are expressed as the mean \pm SEM. Differences were considered statistically significant when $\mathrm{p}<0.05$.

\section{RESULTS}

Mean basal plasma ANP concentrations were significantly higher in the hyperthyroid and significantly lower in the hypothyroid patients compared to the control subjects (Figure 1, Table 1). Compared with normal controls, hyperthyroid patients had faster heart rates, significantly higher systolic blood pressure, elevated serum T3 and T4 levels and lower serum TSH levels while hypothyroid patients had slower heart rate, no significant difference in systolic or diastolic blood pressure, significantly lower serum T3 and T4 levels and higher serum TSH levels. Mean PRA was significantly higher in hyperthyroid patients compared to controls while. In hypothyroid patients no significant differences were detected. Serum ALDO as well as $\mathrm{Na}+$ and $\mathrm{K}+$ levels were not different from controls in either hyperthyroid or hypothyroid patients.

In the groups of 5 hyperthyroid and 8 hypothyroid

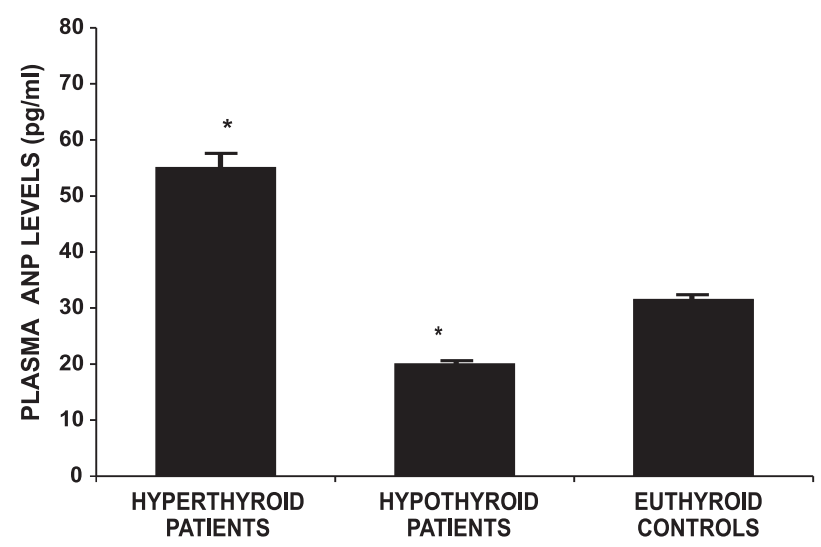

Figure 1. Plasma ANP levels (mean \pm SE) in hyperthyroid and hypothyroid patients and normal controls. $\left({ }^{*} \mathrm{p}<0.001\right.$ compared to controls. Conversion factor to SI units $=0.309$ ).

Table 1. Plasma ANP, thyroid hormones, TSH, aldosterone levels and plasma renin activity as well as heart rate and blood pressure in 16 hyperthyroid and 12 hypothyroid patients (values are expressed as mean $\pm \mathrm{SEM},{ }^{*} \mathrm{p}<0.001,{ }^{*} \mathrm{p}<0.01$ compared to controls).

\begin{tabular}{lccc}
\hline & HYPERTHYROID PATIENTS $(\mathbf{n = 2 1})$ & HYPOTHYROID PATIENTS $(\mathbf{n = 1 2})$ & CONTROL $(\mathbf{n = 2 9})$ \\
\hline ANP $(\mathrm{pmol} / \mathrm{L})$ & $17.0 \pm 1.7^{*}$ & $6.18 \pm 1.14^{* *}$ & $10.35 \pm 0.59$ \\
T4 $(\mathrm{nmol} / \mathrm{L})$ & $253.5 \pm 14.2^{*}$ & $32.2 \pm 3.9^{*}$ & $114.6 \pm 3.9$ \\
T3(nmol/L) & $6.65 \pm 0.49^{*}$ & $0.55 \pm 0.05^{*}$ & $1.77 \pm 0.11$ \\
TSH $(\mathrm{mU} / \mathrm{L})$ & $0.09 \pm 0.005^{*}$ & $82 \pm 13^{*}$ & $1.24 \pm 0.16$ \\
PRA $(\mathrm{nmol} / \mathrm{L} / \mathrm{h})$ & $8.09 \pm 1.3^{* *}$ & $5.62 \pm 1.10$ & $3.04 \pm 0.48$ \\
ALDO (nmol/L) & $0.6 \pm 0.09$ & $0.59 \pm 0.14$ & $0.59 \pm 0.14$ \\
Heart rate (beats/min) & $99 \pm 3.6^{*}$ & $63 \pm 2 *$ & $76 \pm 2.3$ \\
Blood pressure Systolic $(\mathrm{mmHg})$ & $30 \pm 3^{*}$ & $120 \pm 5.3$ & $116 \pm 2.8$ \\
Diastolic (mmHg) & $77 \pm 1.6$ & $80 \pm 3.4$ & $76 \pm 2.2$ \\
\hline
\end{tabular}


patients followed during therapy, mean basal plasma ANP levels were similarly significantly higher and lower, respectively compared to the 6 controls (Table 2). Before therapy, heart rate, serum T3, T4, free T3 and FreeT4 levels were significantly higher in hyperthyroid and lower in hypothyroid patients. Serum TSH levels were almost undetectable in the hyperthyroid and significantly higher than normal in hypothyroid patients. Basal PRA and 24-hour urinary excretion of ALDO and sodium as well as blood pressure were not different from control levels in both groups. Creatinine clearance was significantly lower in hypothyroid patients compared to hyperthyroid patients only before treatment.

The elevated ANP values in the plasma of hyperthyroid were normalized by the 15 th day of treatment to levels not significantly different from those of the normal controls and remained so for the following 60 days (Table 2, Figure 2). Serum T3, T4, Free T3, Free T4 and the heart rate showed a similar pattern. TSH levels on the 15th day of treatment were not different from the pre-treatment levels but thereafter increased and were

Table 2. Changes of plasma ANP, thyroid hormone levels, TSH, plasma renin activity (PRA), urinary aldosterone, heart rate and blood pressure before and during the 60-days period of treatment in 5 hyper and 8 hypothyroid patients (values are expressed as mean \pm SEM, * $\mathrm{p}<0.05$ compared to controls).

\begin{tabular}{|c|c|c|c|c|c|c|}
\hline & \multicolumn{6}{|c|}{ TREATMENT PERIOD (days) } \\
\hline & Before & 15 & 30 & 45 & 60 & Control $(\mathrm{N}=6)$ \\
\hline \multicolumn{7}{|c|}{ HYPERTHYROID PATIENTS (N=5) } \\
\hline \multicolumn{7}{|l|}{ Blood pressure } \\
\hline Systolic (mmHg) & $138 \pm 8$ & $129 \pm 5.1$ & $121 \pm 3.3$ & $119 \pm 5.6$ & $127 \pm 5.4$ & $119 \pm 4.2$ \\
\hline Diastolic (mmHg) & $78 \pm 3.7$ & $81 \pm 4$ & $76 \pm 4$ & $79 \pm 3.3$ & $75 \pm 3.2$ & $76 \pm 2$ \\
\hline Heartrate (beats $\backslash \mathrm{min})$ & $102 \pm 4 *$ & $73.6 \pm 3.2$ & $72 \pm 3.2$ & $69 \pm 2.9^{*}$ & $74 \pm 4.8$ & $83 \pm 4.9$ \\
\hline ANP (pmol/L) & $14.1 \pm 0.87^{*}$ & $9.8 \pm 0.22$ & $9.27 \pm 0.68$ & $8.34 \pm 0.93$ & $8.96 \pm 0.53$ & $9.4 \pm 0.46$ \\
\hline $\mathrm{T} 4(\mathrm{nmol} / \mathrm{L})$ & $256 \pm 27^{*}$ & $90 \pm 26$ & $55 \pm 14$ & $49 \pm 14$ & $68 \pm 19$ & $117 \pm 14$ \\
\hline $\mathrm{T} 3(\mathrm{nmol} / \mathrm{L})$ & $8.93 \pm 1.35^{*}$ & $3.1 \pm 0.41$ & $1.3 \pm 0.27$ & $1.23 \pm 0.22$ & $1.86 \pm 0.33$ & $1.88 \pm 0.33$ \\
\hline FT4 (pmol/L) & $69.8 \pm 10.8^{*}$ & $11.5 \pm 3.50$ & $5.8 \pm 1.90$ & $5.2 \pm 1.16$ & $8.9 \pm 3.10$ & $14.5 \pm 2.31$ \\
\hline FT3 (pmol/L) & $26.6 \pm 3.43^{*}$ & $5.5 \pm 1.25$ & $3.87 \pm 0.91$ & $3.85 \pm 0.89$ & $5.61 \pm 1.31$ & $6.31 \pm 0.92$ \\
\hline TSH (mU/L) & $0.06 \pm 0.01^{*}$ & $0.17 \pm 0.07$ & $9.36 \pm 7.0^{*}$ & $15 \pm 7.6^{*}$ & $19 \pm 10.5^{*}$ & $1.04 \pm 0.27$ \\
\hline PRA (nmol/L/h) & $13.3 \pm 3.0$ & $15.9 \pm 4.7$ & $15.0 \pm 3.6$ & $9.7 \pm 1.8$ & $11.7 \pm 2.8$ & $13.2 \pm 4.0$ \\
\hline Urine ALD (nmol/24h) & $25.1 \pm 2.4$ & $18.3 \pm 1.53$ & $19.8 \pm 6.1$ & $12.2 \pm 2.4$ & $25.5 \pm 8.4$ & $17.5 \pm 5.1$ \\
\hline Urine $\mathrm{Na}+(\mathrm{mmol} / 24 \mathrm{~h})$ & $66.7 \pm 10.1$ & $89.4 \pm 13.4^{*}$ & $73.6 \pm 13.2$ & $62 \pm 8.8$ & $57.3 \pm 19.9$ & $44.8 \pm 11.1$ \\
\hline Creatinine clearance $\left(\mathrm{ml} / 1,73 \mathrm{~m}^{2}\right)$ & $117 \pm 11.3$ & & $105 \pm 10.3$ & & $116 \pm 7.9$ & \\
\hline \multicolumn{7}{|c|}{ HYPOTHYROID PATIENTS $(\mathrm{N}=8)$} \\
\hline \multicolumn{7}{|l|}{ Blood pressure } \\
\hline Systolic (mmHg) & $124 \pm 6.9$ & $122 \pm 6.5$ & $125 \pm 5$ & $120 \pm 8.2$ & $121 \pm 8.3$ & $119 \pm 4.2$ \\
\hline Diastolic (mmHg) & $80 \pm 3.7$ & $78 \pm 3.4$ & $77 \pm 2.9$ & $78 \pm 3.2$ & $76 \pm 4.2$ & $76 \pm 2$ \\
\hline Heartrate (beats $\backslash \mathrm{min})$ & $63.5 \pm 1.9^{*}$ & $73 \pm 3.4$ & $70 \pm 3.1^{*}$ & $75 \pm 5.2$ & $70.9 \pm 3.2$ & $83 \pm 4.9$ \\
\hline ANP (pmol/L) & $4.51 \pm 0.45^{*}$ & $7.0 \pm 0.41^{*}$ & $7.54 \pm 0.56^{*}$ & $8.0 \pm 0.54$ & $7.6 \pm 0.60$ & $9.4 \pm 0.46$ \\
\hline $\mathrm{T} 4(\mathrm{nmol} / \mathrm{L})$ & $35 \pm 3.9^{*}$ & $66 \pm 19$ & $86 \pm 19$ & $84 \pm 19$ & $93 \pm 18$ & $117 \pm 14$ \\
\hline T3 (nmol/L) & $0.53 \pm 0.05^{*}$ & $2.1 \pm 0.38$ & $1.97 \pm 0.36$ & $2.28 \pm 0.51$ & $2.28 \pm 0.42$ & $1.88 \pm 0.33$ \\
\hline FT4 (pmol/L) & $2.45 \pm 0.51^{*}$ & $7.85 \pm 2.96$ & $11.3 \pm 3.35$ & $12.2 \pm 3.47$ & $13.1 \pm 3.22$ & $14.5 \pm 2.31$ \\
\hline FT3 (pmol/L) & $1.28 \pm 0.31^{*}$ & $6.54 \pm 0.82$ & $5.93 \pm 0.65$ & $6.80 \pm 1.29$ & $6.96 \pm 0.77$ & $6.31 \pm 0.92$ \\
\hline TSH (iU/ml) & $71.9 \pm 0.3^{*}$ & $35.9 \pm 4.8^{*}$ & $13.4 \pm 6.0^{*}$ & $11 \pm 6.9$ & $4.5 \pm 3.05$ & $1.04 \pm 0.27$ \\
\hline PRA (nmol/L/h) & $17.8 \pm 1.4$ & $9.2 \pm 1.8$ & $7.5 \pm 4.7$ & $10.0 \pm 3.0$ & $10.5 \pm 2.8$ & $13.2 \pm 4.0$ \\
\hline Urine ALD (nmol/24h) & $22.5 \pm 4.9$ & $24.2 \pm 4.2$ & $23.2 \pm 5.6$ & $23.1 \pm 3.7$ & $22.0 \pm 3.97$ & $17.5 \pm 5.1$ \\
\hline Urine $\mathrm{Na}+(\mathrm{mmol} / 24 \mathrm{~h})$ & $40.5 \pm 8.3$ & $37 \pm 9.5$ & $52 \pm 17.1$ & $55.4 \pm 15$ & $59.5 \pm 11.5$ & $44.8 \pm 11.1$ \\
\hline Creatinine clearance $\left(\mathrm{ml} / 1,73 \mathrm{~m}^{2}\right)$ & $83.3 \pm 5.6^{*}$ & & $92.4 \pm 8.5$ & & $105 \pm 16.8$ & \\
\hline
\end{tabular}




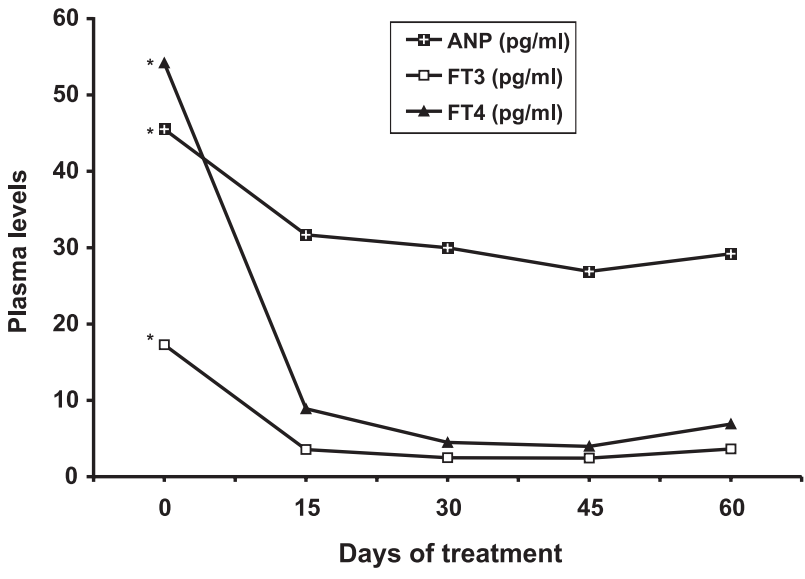

Figure 2. Changes of mean values of plasma ANP, FreeT3 and FreeT4 during the 60-day period of treatment in the group of 5 hyperthyroid patients. ${ }^{*} \mathrm{p}<0.001, \# \mathrm{p}<0.05$. (Conversion factor to SI units for $\mathrm{ANP}=0,309$, FreeT3=1.54 and FreeT4=1.287).

significantly higher than both normal and pre-therapy levels at the 30th, 45th and 60th day. The normalization of thyroid hormone levels had no effect on blood pressure, creatinine clearance, PRA and renal excretion of ALDO at all time periods of the study. Twenty-four-hour sodium excretion did not change significantly during therapy and, when compared to normal subjects, it was significantly higher only at the 15 th day of treatment.

In the hypothyroid patients, plasma ANP levels increased gradually following therapy with thyroxine but were still significantly lower compared to normal controls on the 15th and 30th day of treatment while on the 45th and 60th day of therapy plasma ANP levels, although still lower were not significantly different (Table 2, Figure 3). The low levels of serum thyroid hormones were normalized 15 days after starting 1-thyroxin treatment and did not change significantly up to the end of the followup period, while the high TSH levels decreased gradually and were close to normal 60 days after the initiation of replacement therapy. Normalization of thyroid hormones had no effect on blood pressure, PRA and renal excretion of ALDO and sodium throughout the study, while creatinine clearance remained unchanged.

No correlation was found between plasma ANP levels and serum T3, T4, TSH, ALDO or PRA in the groups of hyperthyroid, hypothyroid or euthyroid subjects. When patients and normal subjects were grouped together, plasma ANP levels were positively correlated with serum T3 $(\mathrm{r}=0.610, \mathrm{p}<0.01), \mathrm{T} 4(\mathrm{r}=0.653, \mathrm{p}<0.01), \mathrm{FT} 3(\mathrm{r}=0.846$, $\mathrm{p}<0.001)$ and FT4 levels $(\mathrm{r}=0.806, \mathrm{p}<0.001)$ (Figure 4), and inversely with serum TSH levels $(\mathrm{r}=-0.519, \mathrm{p}<0.01)$,
(Figure 5). It should be noted, however, that a strong positive correlation was observed between plasma ANP and pulse rate $(r=0.704, p<0.01)$ (Figure 5) while systolic and diastolic blood pressure as well as PRA and serum ALDO were not correlated with plasma ANP levels. A multiple regression analysis showed that T3, T4 and pulse rate $(\beta$ coefficient $0.117 ; \mathrm{p}<0.001,0.272$; $\mathrm{p}<0.001,0.592 ; \mathrm{p}<0.001$, respectively) significantly correlated with ANP levels.

\section{DISCUSSION}

Atrial natriuretic peptide, a hormone synthesized by atrial cardiocytes ${ }^{1,8}$ and involved in blood pressure and electrolyte homeostasis ${ }^{23}$, is released into the circulation in response to increased atrial distension and stretching $^{24,25}$. Experimental studies on rats, both in vivo and in vitro, have provided evidence that ANP secretion is influenced by thyroid hormones ${ }^{26,27}$.

The majority of pertinent studies have shown that ANP levels in patients with untreated hyperthyroidism and hypothyroidism were significantly different from those of normal subjects ${ }^{18,19,26,28-31}$ and returned to normal after appropriate treatment. However, at least in one study different results were detected ${ }^{22}$. Our findings are in accordance with the reports that plasma ANP levels are increased in patients with hyperthyroidism and decreased in patients with hypothyroidism and return to normal after euthyroid state is accomplished.

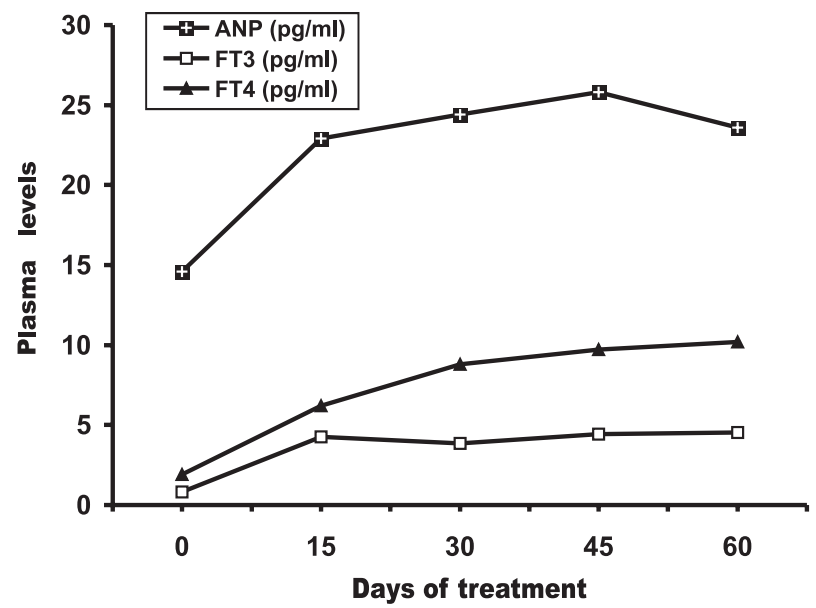

Figure 3. Changes of mean values of plasma ANP, FreeT3 and FreeT4 during the 60-day period of treatment in the group of 8 hypothyroid patients. ${ }^{*} \mathrm{p}<0.01$. (Conversion factor to SI units for $\mathrm{ANP}=0,309$, FreeT3=1.54 and FreeT4=1.287). 

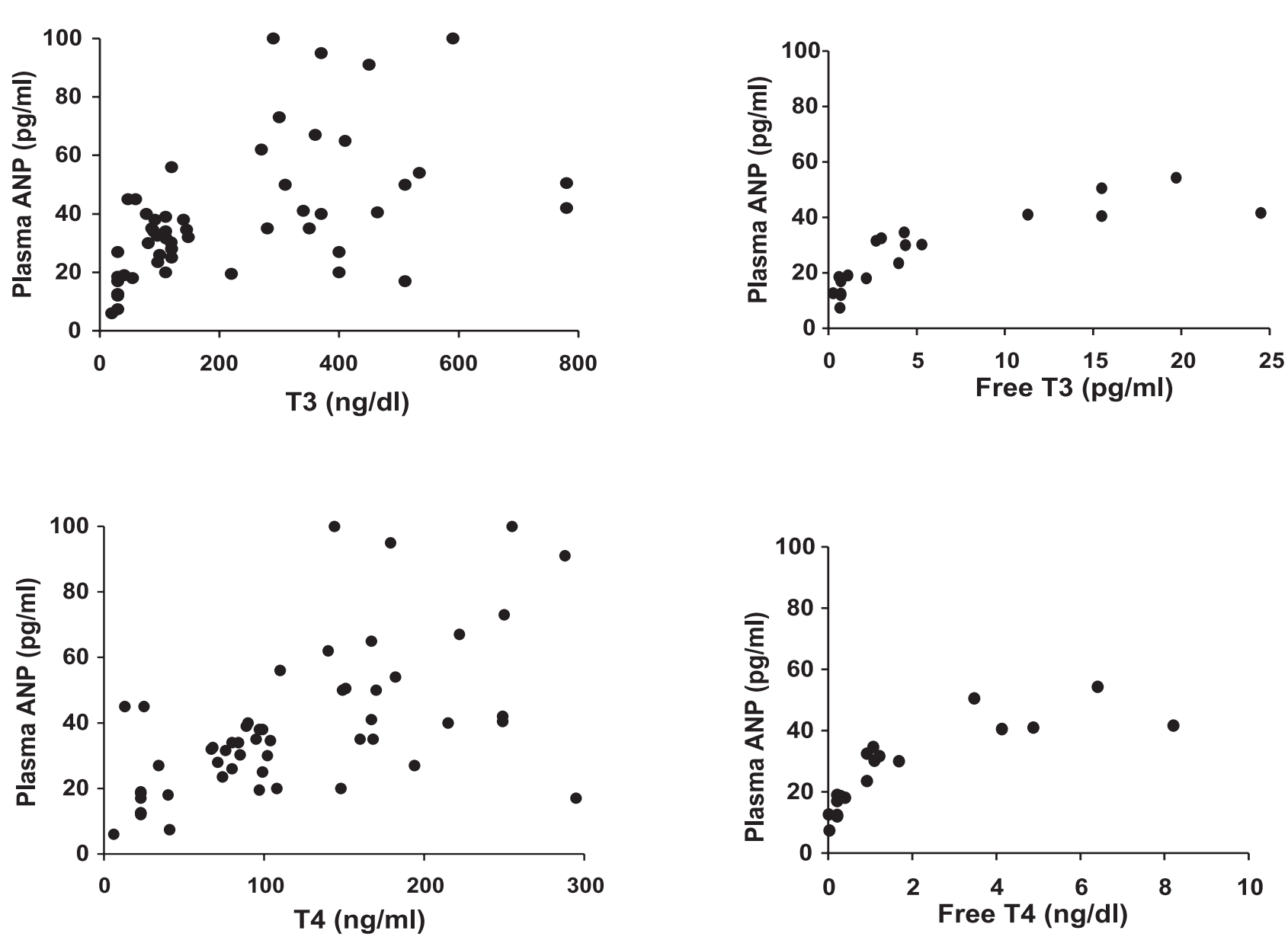

Figure 4. Relationship between plasma ANP and total T3 $(r=0.610, p<0.01)$, FreeT3, $(r=0.846, p<0.001)$, total T4 $(r=0.653$, $p<0.01)$, and FreeT4 $(r=0.806, p<0.001)$ levels in pooled together hyperthyroid and hypothyroid patients and normal controls.

Our data suggest that thyroid hormones affect the production of ANP. Thus, in hyperthyroid patients, the reduction of serum thyroid hormones to normal levels after appropriate therapy was followed by a parallel normalization of plasma ANP while in hypothyroid patients plasma ANP, reached levels not significantly different from controls 45 days after therapy initiation.

The thyroid hormone action on renin synthesis and release has been studied in vivo and $\mathrm{n}$ vitro ${ }^{32,33}$. Thyroid hormones affect positively renal renin synthesis and release. Thus, a stimulatory effect has been observed in hyperthyroidism and an inhibitory in hypothyroidism. Our data of increased PRA in hyperthyroid patients and unchanged PRA in hypothyroid patients support the former but not the latter observations. In rats, thyroid hormones activate the renin-angiotensin system increasing significantly the PRA and plasma Ang-II levels, while the opposite effect was observed in the hypothyroid state $^{34}$. The increase of PRA in hyperthyroid patients is attributed to enhancement of renin secretion and higher conversion of inactive to active renin ${ }^{35}$ possibly by an increased sympathetic activity since beta-blocker, propranolol, returned the PRA to normal ${ }^{36}$. It has been suggested that these changes could be related to adrenergic alterations since they constitute one of the mechanisms involved in the control of renin release by juxtaglomerular cells ${ }^{37}$. The absence of any significant alterations of PRA in hyperthyroid and hypothyroid patients studied for two months during therapy could be explained by decreased adrenergic activity and cardiovascular stability attributed to supine position for many hours before blood collection.

Serum aldosterone levels were not different between hyperthyroid patients and normal subjects although the former had significantly higher PRA, a finding also reported in other studies ${ }^{34,38,39}$. The data indicate an inhibitory effect of ANP on Ang-II-induced ALDO secretion in hypethyroidism. This inhibitory effect of ANP on 

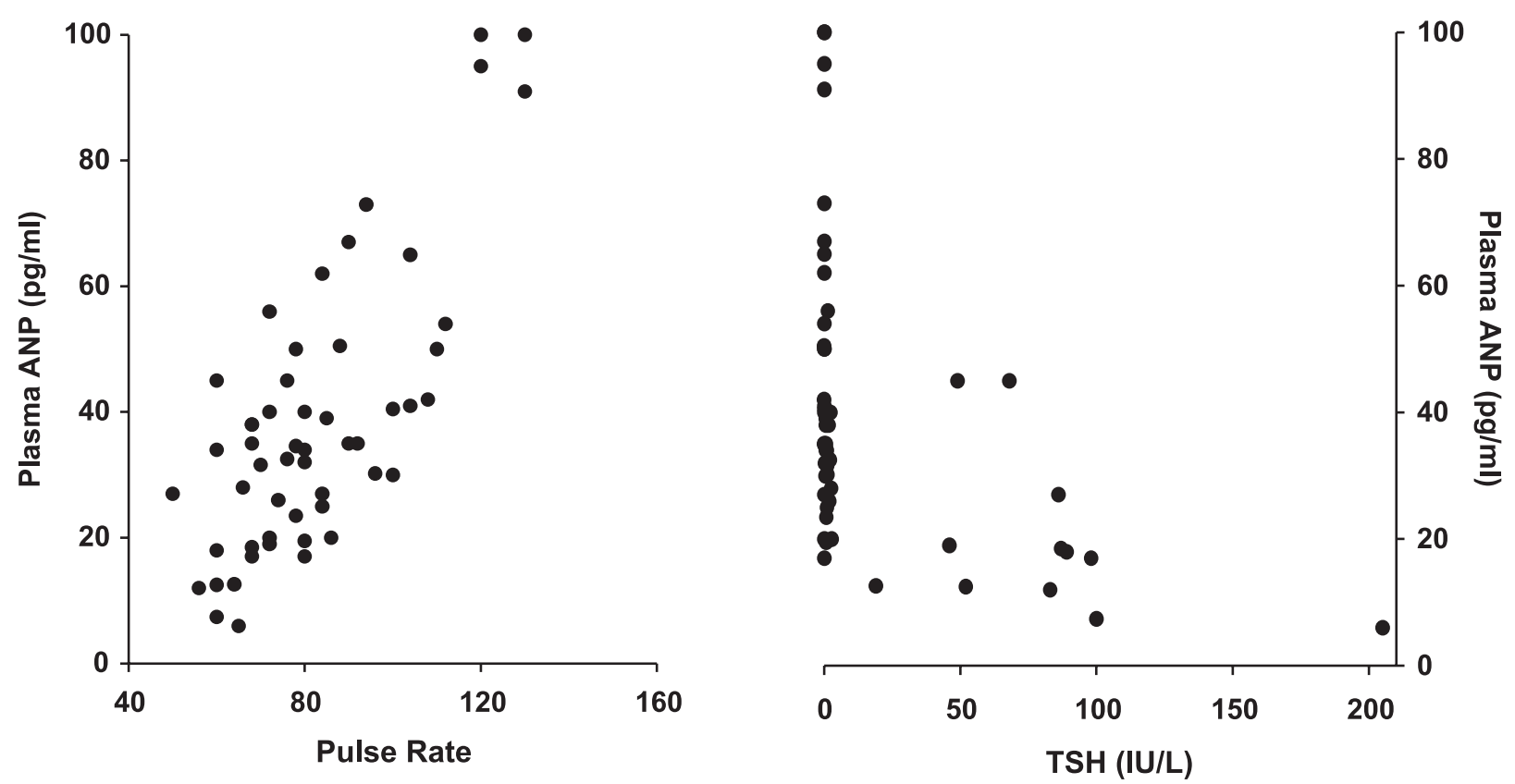

Figure 5. Relationship between plasma ANP levels and pulse rate $(r=0.704, p<0.01)$ as well as TSH levels $(r=-0.519$, $p<0.01)$ in pooled together hyperthyroid and hypothyroid patients and normal controls.

ALDO secretion has also been shown in cultured rat and human adrenal zona glomerulosa cells ${ }^{39,40}$ as well as in vivo in normal subjects ${ }^{41}$ and in hyperthyroid patients by the administration of a graded Ang-II infusion ${ }^{39}$. The above observations indicate that thyroid hormones stimulate the secretion of ANP from the myocardium which then antagonizes the effects of the renin system on the adrenals and the arterial bed.

In agreement with previously published data ${ }^{19,20,26}$, we have found a strong positive correlation between ANP and thyroid hormone levels. Whether thyroid hormones influences directly and/or indirectly the secretion of ANP remains unclear. The significant decrease of ANP levels which accompanied the normalization of serum thyroid hormone concentrations in hyperthyroid patients as well as the increase of ANP levels in hypothyroid patients after appropriate thyroid hormone replacement in the present as well as in other studies ${ }^{17,26,31,42}$ confirm the importance of thyroid hormones in the control of ANP secretion. Furthermore circulating thyroid hormone levels have been shown, in vivo, to correlate positively with atrial and ventricular ANP mRNA contents ${ }^{43}$.

We have also found that pulse rate correlated positevely with plasma ANP levels. The excess of thyroid hormones is associated with increased heart rate, blood volume, cardiac contractility and cardiac output ${ }^{44}$ and decreased systemic vascular resistance, while the opposite is observed in thyroid hormone deficiency ${ }^{21}$. The fact that in intact animals as well as in humans the artificial ventricular pacing increases the secretion of $\mathrm{ANP}^{45}$, despite normal thyroid hormone levels, indicates the existence of another mechanism for the regulation of ANP secretion. This mechanism appears to remain intact in hyperthyroidism as deduced from hyperthyroid patients with atrial fibrillation who had significantly higher plasma ANP levels compared to patients without atrial fibrillation ${ }^{42}$. Thyroid hormone-dependent hemodynamic effects seem to be superimposed on the direct stimulatory effect of thyroid hormones on ANP production by cardiocytes. However, the propranolol-depressed heart rate in hyperthyroid patients failed to affect ANP secretion $^{38}$.

In conclusion, our findings show that thyroid hormones regulate positively ANP production from cardiac myocytes. It is our hypothesis that this effect of thyroid hormones is exerted both directly on cardiac myocytes and indirectly via alterations of the cardiovascular system resulting in increased atrial stretch.

\section{REFERENCES}

1. DeBold AJ, Borenstein HB, Veress AT, Sonnenberg H. 1981 A rapid and potent natriuretic responce to intravenous injection of atrial myocardial extract in rats. Life Sci 28:89-94. 
2. Ballerman BJ, Brenner BM. 1986 Role of the atrial peptide in body fluid homeostasis. Circ Res 58:619-630.

3. DeBold AJ 1982 Atrial natriuretic factor of the rat heart. Studies on isolation and properties. Proc Soc Exp med 170:133-37.

4. Antunes-Rodrigues J, McCann SM, Rogers LC, Samson WK. 1985 Atrial natriuretic factor inhibits dehydrationand angiotensin II-induced water intake in the conscious, unrestrained rat. Proc Natl Acad Sci USA 82:8720-8723.

5. Masoto C and Negro-Vilar A. 1985 Inhibion of spontaneous or angiotensin II-stimulated water intake by atrial natriuretic factor. Brain Res Bull 15:523-526.

6. Antunes-Rodrigues J, McCann SM, Samson WK. 1986 Central administration of atrial natriuretic factor inhibits saline preference in the rat. Endocrinology 118:17261728.

7. Franci CR, Kozlowski GP, McCann SM. 1989 Water intake in rats subjected to hypothalamic immunoneutralization of angiotensin II, atrial natriuretic peptide, vasopressin, or oxytocin. Proc Natl Acad Sci USA 86:29522956.

8. Currie MG, Geller DM, Cole BM. 1983 Bioactive cardiac substances: potent vasorelaxant activity in mammalian atria. Science 221:71-73.

9. Kleinert HD, Maack T, Atlas SA, Januszewicz A, Sealey JE, Laragh JH. 1984 Atrial natriuretic factor inhibits angiotensin, norepinephrine and potassium-indused vascular contractility. Hypertension 6 (Suppl I):I143-147.

10. Camargo MJF, Kleinert HD, Atlas SA, Sealey JE, Laragh JH, Maack T. 1984 Ca-dependent hemodynamic and natriuretic effects of atrial extract in isolated rat kidney. Am J Physiol 246:F447-F456.

11. Winquist RJ, Faison EP, Waldman SA, Schwartz K, Murad $\mathrm{F}$ et al. 1984 Atrial natriuretic factor elicits an endothilium indipendent relaxation and activates particulate guanylate cyclase in vascular smooth musle. Proc Natl Acad Sci USA 81:7661-7664.

12. Burnett JC Jr, Granger JP, Opgenorth TS. 1984 Effects of synthetic atrial natriuretic factor on renal function and renin release. Am J Physiol 247:F863-F866.

13. Maack T, Marion DN, Camargo MJF, et al. 1984 Effects of auriculin (atrial natriuretic factor) on blood pressure, renal function and the renin-aldosterone system in dogs. Am J Med 77:1069-1075.

14. Woolf AS and Moult PJA. 1987 Plasma levels of atrial natriuretic peptide in hyperthyroidism. Clin Endocrinol (Oxf) 27:721-725.

15. Everett AW, Sinha AM, Umeda PU, Jakovcic B, Rabinowitz M, Zak N. 1984 Regulation of myosin synthesis by thyroid hormone: relative change in the a- and b-myosin heavy chain mRNA levels in rabbit heart. Biochemistry 23:1596-1599.

16. Argentin S, Drouin J, Nemer M. 1987 Thyroid hormone stimulates rat pro-natriodilantin mRNA levels in primary cardiocyte cultures. Biochem Biophys Res Commun 146:1336-1341.

17. Kohno M, Murakawa K, Yasunari K, Morii H, Takeda T. 1987 Circulating atrial natriuretic peptides in hyperthy- roidism and hypothyroidism. Am J Med 83:648-652.

18. Rolandi E, Santaniello B, Bagnasco M, Cataldi A, Garibaldi C, Franceschini R, barreca T. 1992 Thyroid hormones and atrial natriuretic hormone secretion: study in hyper- and hypothyroid patients. Acta Endocrinol (Copenh) 127:23-26.

19. Widecka K, Gozdzik J, Dutkiewitcz T, Majewska U, Czekalski S. 1990 Atrial natriuretic factor in untreated hyperthyroidism. Ann Clin Biochem 27:313-317.

20. Parlapiano C, Campana E, Alessandri N, Rota C, Sellini M, Vecci E, Tonnarini G, Borgia MC, Negri M. 1998 Plasma atrial natriuretic hormone in hyperthyroidism. Endocr Res 24:105-112.

21. Dieckman Mj, Harms MP, Endert E, Wieling W, Wiersinga WM. 2001 Endocrine factors related to changes in total peripheral vascular resistance after treatment of thyrotoxic and hypothyroid patients. Eur J Endocrinol 144:339-346.

22. Ladenson PW, Michener M, Langevin H. 1986 Plasma and atrial atripeptin concentrations in hyperthyroid, euthyroid, and hypothyroid rats. In: Proceedings of the 68th Annual meeting of the Endocrine Society, Anaheim, Callifornia USA, 235.

23. Laragh JH 1985. Atrial natriuretic hormone, the reninaldosterone axis and blood pressure- electrolyte homeostasis. N Engl J Med 313:1330-40.

24. Edwards BS, Zimmerman RS, Schwab TR, Heublein DM, Burnett JC. 1988 Atrial strech, not pressure, is the principal determinant controlling the acute release of atrial natriuretic factor. Circul Res 62:191-195.

25. Dietz JR. 1984 Release of a natriuretic factor from rat heart-lung preparation by atria distention. Am J Physiol 247:R1093-1096.

26. Kohno M, Takaori K, Matsuura K, Kanayama Y, Takeda T. 1986 Atrial natriuretic polypeptide in atria and plasma in experimental hyperthyroidism and hypothyroidism. Bioch Biophys Res Commun 134:178-183.

27. Matsubara H, Hirata Y, Yoshimi H 1987 Effects of steroid and thyroid hormones on synthesis of atrial natriuretic peptide by cultured atrial myocytes of rat. Bioch Biophys Res Commun 145:336-343.

28. Zimmerman RS, Gharib H, Zimmerman D, Henblein D, Burnett JC Jr, 1987 Atrial natriuretic peptide in hypothyroidism. J Clin Endocrinol Metab 64:353-355.

29. Vesely DL, Winters CJ, Sallman A. 1989 Prohormone atrial natriuretic peptides 1-30 and 31-67 increase in hyperthyroidism and decrease in hypothyroidism. Am J Med Sci 297:209- 215.

30. Widecka K, Gozdzik J, Dutkiewitcz T, Mamos E, Czekalski S, 1990 Low plasma concentrations of atrial natriuretic peptide in untreated hypothyroid patients. $\mathrm{J}$ Int Med 228:39-42.

31. Woolf AS and Moult PJA. 1987 Plasma levels of atrial natriuretic peptide in hyperthyroidism. Clin Endocrinol (Oxf) 27:721-725.

32. Hauger-Klevene JH, DeVito E, Fasciolo JC. 1977 The effect of thyroid hormones on renin production and release by rat kidney slices. Acta Physiol Latinoam 27:37-41. 
33. Ganong WF. 1982 Thyroid hormones and renin secretion. Life Sci 30:561-569.

34. Marchant C, Rown L, Sernia C. 1993 Renin-angiotensin system in thyroid dysfunction in rats. J Cardiovasc Pharmacol 22:449-455.

35. Baba T, Murabayashi S, Aoyagi K, Kitaoka M, Nakazomo M, et al. 1986 Plasma renin activity, active and inactive renin concentrations, and their responses to beta 1adrenoreceptor blockade with metoprolol in hyperthyroidism. Horm Metab Res 18:630-634.

36. Montiel M, Jimenez E, Navaez JA, Morrel M. 1984 Aldosterone and plasma renin activity in hyperthyroid rats: effects of propranolol and propylthiuracil. J Endocrinol Invest 7:559-562.

37. Hauger-Klevene JH. and Levin GH. 1976 Kinetic of the renin system in hyper- and hypothyroidism. Medicina 36:219-222.

38. Shigematsu S, Iwasaki T, Aizawa T, Ishihara M, Shinoda T, et al. 1989 Plasma atrial natriuretic peptide, plasma renin activity and aldosterone during treatment of hyperthyroidism due to Graves' disease. Hormon Metab Res 21:514-518.

39. Kigoshi T, Kaneko M, Nakano S, Azukizawa S, Uchida K, Morimoto S. 1993 Aldosterone response to various stimuli in hyperthyroidism: in vivo and in vitro studies. Nippon-Naibuppi-Gokkai Zasshi 69:609-620.

40. Higuchi K, Nauata H, Kato K, Ibayashi H, Matsuo H.
1986 a-human atrial natriuretic polypeptide inhibits steroidogenesis in cultured human adrenal cells. J Clin Endocrinol Metab 62:941-944.

41. Weidmann P, Hellmuller B, Uehlinger DE, Lang RE, Grandinger MP, Hasler L, Shaw S, Bachmann C. 1986 Plasma levels and cardiovascular, endocrine, and excretory effects of atrial natriuretic peptide during different sodium intakes in man. J Clin Endocrinol Metab 62:10271036.

42. Czekalski S, Widecka K, Gozdzik J, Ciechanowski K, Krzyzanowska-Swiniarska B, et al.1994 Atrial natriuretic peptide and cyclic guanosine monophosphate plasma concentrations in patients with thyrotoxicosis and atrial fibrilation. Effect on short-term methimazole therapy. J Endocrinol Invest 17:341-346.

43. Ladenson PW, Bloch KD, Seidman JG. 1988 Modulation of atrial natriuretic factor by thyroid hormone: Messenger ribonucleic acid and peptide levels in hypothyroid, euthyroid and hyperthyroid rat atria and ventricles. Endocrinology 123:652-657

44. Smallridge RC, Goldman MH, Raines K, et al. 1987 Rest and exercise left ventricular ejection fraction before and after therapy in young adults with hyperthyroidism and hypothyroidism. Am J Cardiol 60:929-931.

45. Osborn MJ, Hammil SC, Burnett JC Jr. 1986 Enhanced levels of circulating atrial natriuretic peptide during ventricular pacing in humans (abstr). J Am Coll Card 7:A192. 